\title{
Forecasting non-linear WPI of manufacture of chemicals and chemical products in India: an MLP approach
}

\author{
Dipankar Das ${ }^{1 *}$ and Satyajit Chakrabarti ${ }^{2}$ \\ Research Scholar, University of Engineering \& Management, Kolkata, West Bengal, India ${ }^{1}$ \\ Professor, University of Engineering \& Management, Kolkata, West Bengal, India ${ }^{2}$
}

Received: 12-July-2021; Revised: 20-September-2021; Accepted: 24-September-2021

(C2021 Dipankar Das and Saty ajit Chakrabarti. This is an open access article distributed under the Creative Commons Attribution (CC BY) License, which permits unrestricted use, distribution, and reproduction in any medium, provided the original work is properly cited.

\begin{abstract}
Forecasting is an instrument of decision-making that makes predictions or estimates about the future based on historical data. Identifying a suitable strategy for forecasting a time series amongst the classical techniques (e.g., exponential smoothing, Auto-Regressive Integrated Moving Average (ARIMA)), Neural approach, and Support Vector Regression (SVR) - another widely used and popular machine learning-based approach, is challenging. The present work aimed at providing a simple (implementation wise), efficient (forecast accuracy wise), and state-of-art Multi-Layer Perceptron (MLP) approach for some selected macroeconomic indices (Wholesale Price Index - i.e., WPI) in India. We looked at the WPIs with non-linear trends identified using the curve-fit method. It's known that the diverse Indian chemical industry contributes notably to India's economic development. In this work, we analyzed the WPI of seventy-seven commodities/items of the "manufacture of chemicals and chemical products" group in India. We detected the indices having non-linear trends by applying the curve-fit method. The curve-fit approach based on statistical rigor identifies the non-linear WPIs. Twenty-five out of seventy-seven indices exhibits non-linear trends. We developed a forecasting approach employing the MLP for these twenty-five non-linear WPIs. The proposed-MLP optimized by hyperparameter tuning offers high accuracy, prediction reliability, and prediction acceptability for all non-linear WPIs. The forecasting performances of the proposed-MLP compared with regression models (Linear, Quadratic, Cubic, Logarithmic, Exponential), exponential smoothing (Holt linear trend, Holt exponential trend, Holt-Winters), state-of-art Auto-ARIMA, and SVR. The MLP outperformed them all. In terms of Mean Absolute Percentage Error (MAPE), the MLP outperform Linear in 88\%, Quadratic in 92\%, Cubic in 88\%, Logarithmic in 72\%, exponential in 88\%, Holt Linear in $80 \%$, Holt Exponential in 76\%, Holt-Winters in 72\%, Auto-ARIMA in 56\%, and SVR in 56\% of cases. We suggest the application of the proposed approach as an alternative for forecasting these twenty-five non-linear WPIs.
\end{abstract}

\section{Keywords}

Curve fitting, Multilayer perceptron, Wholesale price index, ARIMA, Exponential smoothing, Support vector regression.

\section{Introduction}

Forecasting predicts/ estimates the future by taking into account historical data. It's an instrument of decision-making that assists companies/ enterprises/ institutions in managing uncertainties. It allows the business to set up goals and create a budget. Forecasting helps us to anticipate changes and therefore guide us towards data-driven strategies and reasoned decisions/ choices. It serves as a more proactive rather than a reactive measure.

\footnotetext{
*Author for correspondence
}

1193
There are several forecasting approaches for the univariate Time Series (TS) data, e.g., AutoRegressive Integrated Moving Average (ARIMA) [13], Exponential Smoothing (ES) [4-6], Support Vector Regression (SVR) [7, 8, 9], neural approaches [10-12]. The recent studies show that the researchers employed these approaches for forecasting various TS data, e.g., stock prices [1, 2, 13], prices of agricultural products $[4,5,6]$, the price index $[10$, 14].

India's chemical industry is highly diverse, covers a wide range of products, and has a large import and export base. More than two million people are working here. On the economic growth of India, this sector's contribution is notable. In the future, there 
exists a significant opportunity for the industry's business/ revenue growth.

In India, on the economic front, there exist several indicators. We can use these indicators to assess and forecast the performance of different sectors. We know that the Wholesale Price Index (WPI) is an indicator that monitors the price changes of goods before they reach the retail stage. The selling of these goods/items is in bulk and transacted between businesses. India's WPI series, the current one, has the base 2011-12 = 100 and lists seventy-seven commodities in the "manufacture of chemicals and

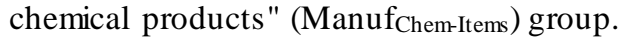

To suggest an appropriate forecasting strategy for the WPIs having non-linear trends from the Manuf Chem- $_{\text {- }}$ Items group in India that is simple (implementation wise) and efficient (forecast accuracy wise) and can act as a convenient alternative is a challenge. Motivated by this, the objectives of this work are as follows:

- Trend examination of the monthly WPIs of seventy-seven commodities of the ManufChem-Items group of India's current WPI series. The data is of forty-eight months, starting in April 2012 and ending in March 2016.

- Identification of the WPIs of Manuf $f_{\text {Chem-Items }}$ group having a non-linear trend (WPI NonLinear $_{\text {) during this }}$ period.

- Model development for the $\mathrm{WPI}_{\text {NonLinear indices }}$ suitable to render twelve months ahead forecasts.

In this work, we analyzed these seventy-seven WPIs, identified those that have non-linear trends by applying the curve fit, and developed forecast models for these identified WPIs. An Artificial Neural Network (ANN) is a computational tool used for solving complex problems Marini [15], non-linear data modeling Bertolaccini et al. [16], and suitable for learning non-linear relationships and modeling them [17]. In this work, for forecasting the non-linear WPIs, we employed the Multi-Layer Perceptron (MLP) - a class of ANN.

\section{Literature review}

Wadi et al. [1] found the best-fit ARIMA model for forecasting the closed price of Jordan's ASE, with $p$, $\mathrm{d}$, and q parameters of 2, 1 , and 1 correspondingly, and Root Mean Squared Error $(\mathrm{RMSE})=4$. For the banking stock data of Jordan's ASE, the ARIMA $p=1$, $\mathrm{d}=1$, and $\mathrm{q}=2$ suited most with RMSE=1.4 Almasarweh and Alwadi [2]. While forecasting the trucking prices in the US, Miller [3] found that the 1194
ARIMA with $\mathrm{p}=1, \mathrm{~d}=1$, and $\mathrm{q}=0$ best fitted to forecast the Truckload. BLS data. Azari [18] used ARIMA to predict the bitcoin price and witnessed increased MSE due to the price fluctuations of the bitcoins when working with the closing price. Hossain et al. [13] found the best-fitted ARIMA model for forecasting the banking stock data of Bangladesh's DSE is having $\mathrm{p}=0, \mathrm{~d}=2$, and $\mathrm{q}=1$ parameters and produced $\mathrm{MAPE}=1.632$, and $\mathrm{RMSE}=0.046$. Zhu et al. [19] used this approach using $\mathrm{p}=1, \mathrm{~d}=1$, and $\mathrm{q}=1$ to forecast COVID-19 cases in China. Katoch and Sidhu [20] forecast India's COVID-19 confirmed cases using the method having $\mathrm{p}=4, \mathrm{~d}=2$, and $\mathrm{q}=7$.

Talwar and Goyal [4] applied different ES approaches to predict Indian coriander price and observed Holt-Winters trend-adjusted model with alpha $=1$ and beta $=0.06$ performs best, and the model showed RMSE $=100.11$. In production forecasting of Thailand's crude palm oil, Suppalakpanya et al. [5] studied various ES techniques, observed that additive Holt-Winters and extended additive Holt-Winters exhibited the smallest MAPE. To forecast the price of potatoes in Turkey, Şahinli [6] used ARIMA, HoltWinters additive, and Holt-Winters multiplicative approaches and found the ARIMA model with $\mathrm{p}=1$, $\mathrm{d}=1$, and $\mathrm{q}=2$ is the best. Rasheed et al. [21] forecast the PKR's exchange rate using the ES technique and obtained MAPE=6.53. Sokannit and Chujai [22] applied the triple ES to forecast electricity (household consumption). Li et al. [23] found the multiplicative Holt-Winters is a suitable approach to predict the agriculture and forestry's gross output value in Guangxi, China. While performing the forecast of Indonesian construction companies' share prices, Ali [24] noted that Holt's double ES method is suitable for forecasting.

In forecasting the Spanish tourism demand, the SVR using RBF kernel outdid the ARMA approach Claveria et al. [7]. The SVR method with $c=6$ and gamma $=0.01$ beats the ARIMA model with $\mathrm{p}=0, \mathrm{~d}=1$, and $\mathrm{q}=1$ parameters, simple ES model with alpha $=0.9$, and Moving Average model in forecasting US crude oil prices He [8]. Carrasco et al. [25] examined the application of the Support Vector Machine (SVM) in predicting the London Metal Exchange's copper price and observed good performance of the approach. Kuizinienè et al. [9] forecast cryptocurrencies using SVR with a linear kernel and ARIMA, found that ARIMA beat SVR. Rohmah et al. [14] examined the SVR method's following four different Kernels in forecasting the 
Consumer Price Index (CPI) of Indonesia: Linear, Polynomial, Spline, and Gaussian-RBF. The authors Rohmah et al. [14] observed that the Gaussian-RBF outperformed other kernels and found it more suitable for forecasting the CPI. In forecasting Hong Kong's property price index, the authors Abidoye et al. [10] contrasted the ARIMA methodology to two well-known AI approaches: (i) SVM and (ii) Artificial Neural Network (ANN) [10]. They employed the "backpropagation multilayer perceptron ensemble" algorithm to train the ANN. Airlangga et al. [11]compared the backpropagationANN and four ES methods - single, double, additive triple, and multiplicative triple for forecasting the Indonesian rice production where the former outperformed the ES methods . Spiliotis et al. [12] applied various statistical and ML approaches to predict Belgium's electricity prices, observed the MLP outperformed the naïve Bayes, ES, multiple linear regression, and seasonal ARIMA approaches. To forecast the BCG vaccine demand in Cabanatuan city, the Philippines, the authors Alegado and Tumibay [26] found the MLP having 16/5/1 architecture showed MSE $=31.79$ and exceeded the ARIMA. To forecast the COVID-19 confirmed cases in Iran, Talkhi et al. [27] showed that the MLP performed well with a low Mean Absolute Percentage Error (MAPE) (5.72 approx.).

From the literature reviewed, the author's observations are the followings:

- Different ES approaches and ARIMA were widely employed on several TS data and provided efficient results (forecast accuracy wise).

- Researchers applied various machine learning approaches (e.g., neural approach, SVR) for univariate TS forecasting and obtained efficient results.

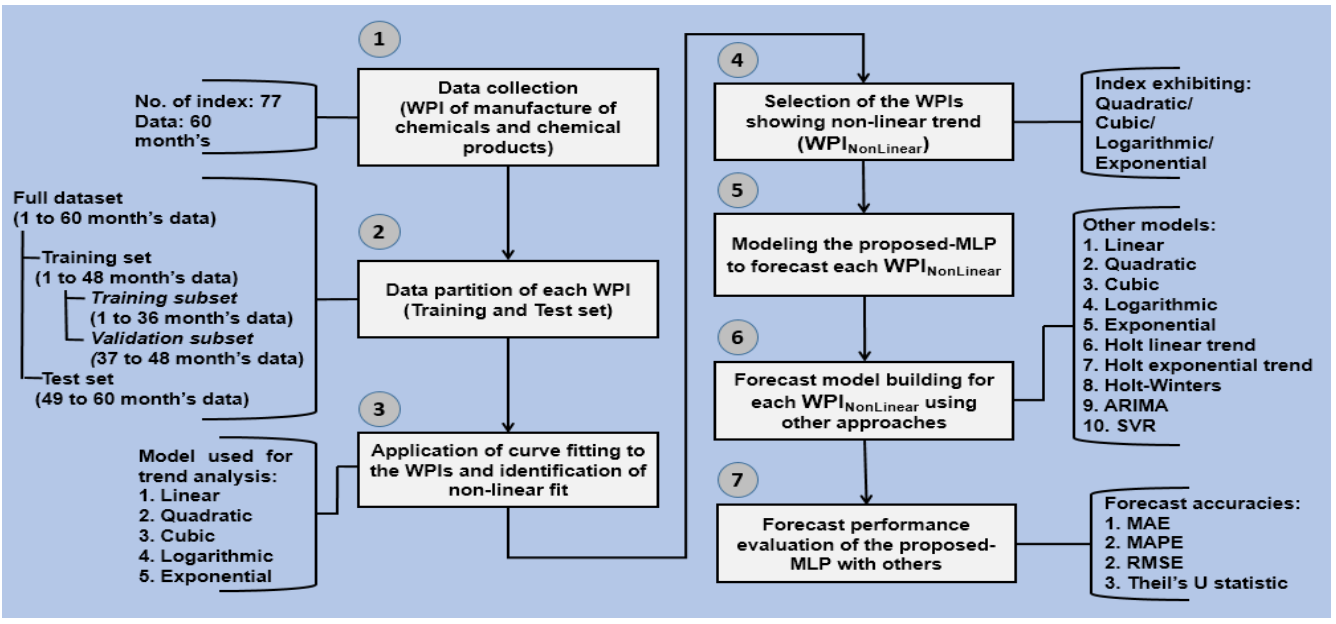

Figure 1 Methodology of MLP modeling of the WPI $\mathrm{NonLinear}_{\text {of }}$ Manuf $\mathrm{Chem-Items}_{\text {group }}$ 1195
- In studies, the researchers pointed out the neural approaches are suitable for learning non-linear relationships and modeling them.

The authors further identified the following research gaps in the recent studies: application of the TS forecasting techniques - (a) regression models, (b) different ES techniques, (c) ARIMA approach, (d) MLP approach, and (e) SVR approach for forecasting the non-linear WPIs of India from the "manufacture of chemicals and chemical products" group.

The present work aims at bridging the gaps by identifying the non-linear WPIs from the said set, developing a simple (implementation wise), efficient (forecast accuracy wise), and state-of-art MLP approach for forecasting these non-linear WPIs, and comparing its performance with the results of other techniques to analyze the quality of the proposed approach.

\section{Methodology}

The methodology used is portrayed graphically in Figure 1. The authors employed the following seven distinct steps to approach their objectives: (a) data collection (Step1), (b) data partition (Step2), (c) application of curve fitting to the WPIs of ManufChemItems group, and identification of non-linear fit (Step3), (d) selection of the WPIs of Manuf Chem-items group showing non-linear trend (Step4), (e) modeling the

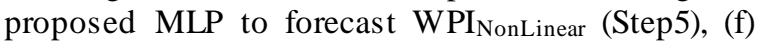
forecast model building for the WPI NonLinear $_{\text {using }}$ other approaches (Step6), and (g) forecasting performance evaluation (Step7). The steps are discussed in detail in 3.1 to 3.7. 


\subsection{Data collection (Step1)}

We gathered the monthly data of all the seventyseven commodities listed in the Manuf $\mathrm{Chem}_{\text {-Items }}$ group of India's current WPI series. The data is of sixty months, starting in April 2012 and ending in March 2017. We gathered the data from the data.gov.in platform [28].

\subsection{Data partition (Step2)}

We partitioned the data into two parts - training and test sets. The training set is again further subdivided into the training and validation subsets. Figure 2 represents the data division scheme of the present work.

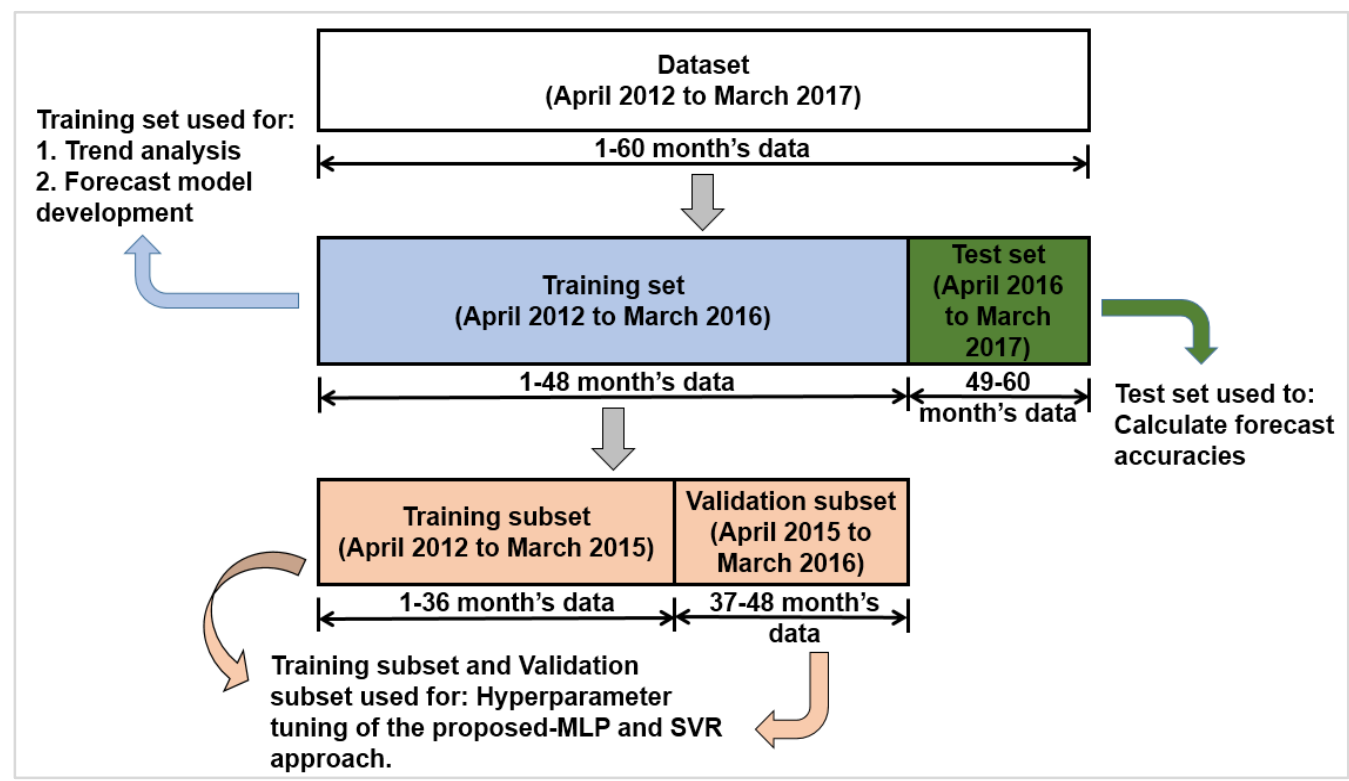

Figure 2 Data division scheme of WPIs of Manuf Chem-Items $_{\text {group }}$

3.3Application of curve fitting to the WPIs of

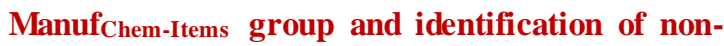
linear fit (Step3)

For each WPI, Figure 3 describes the process of nonlinear trend determination achieved through curve fitting. The curve best fitted gave us the result. We used the $\mathrm{lm}$ function of R's stats package for fitting curves to data points [29].

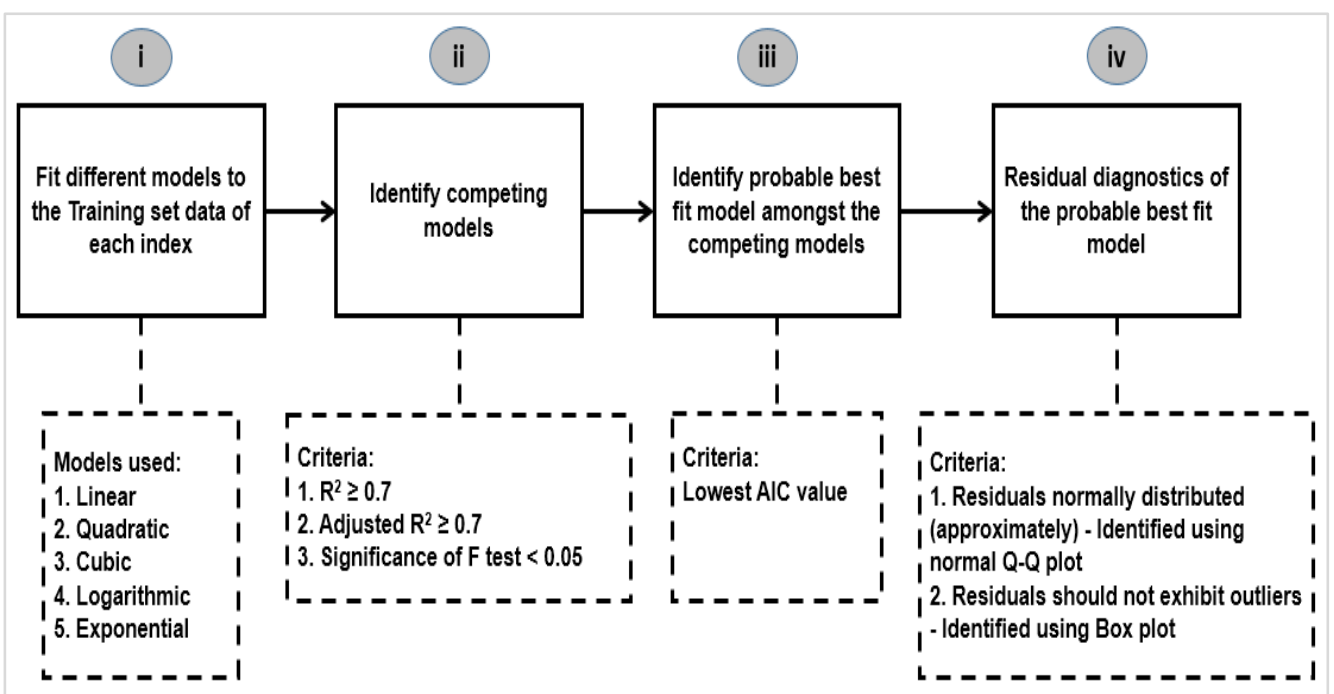

Figure 3 Curve fitting to the WPIs of Manuf $f_{\text {Chem-Items }}$ group and best fit identification 
3.4 Selection of the WPIs of Manuf Chem-items $_{\text {group }}$ showing non-linear trend (Step4)

If a WPI showed Quadratic/ Cubic/ Logarithmic/ Exponential best fit, we identified it as a non-linear trend exhibiting index. The WPIs showing non-linear trend (WPINonLinear) is selected.

3.5Modeling the proposed MLP to forecast WPINonLinear (Step5)

The MLP architecture offered to forecast the WPINonLinear is portrayed in Figure 4.

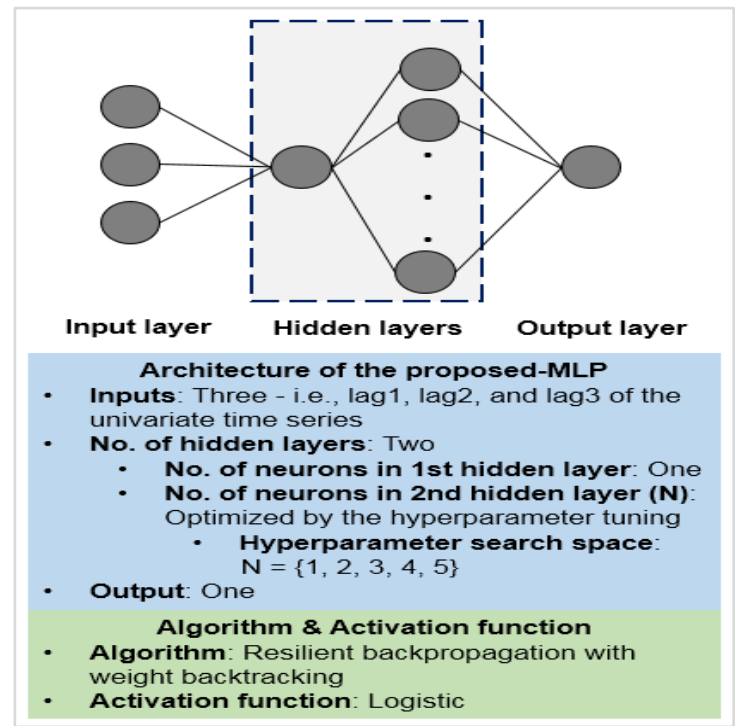

Figure 4 MLP architecture for forecasting WPI $_{\text {NonLinear }}$

We performed hyperparameter tuning of the MLP model for each $\mathrm{WPI}_{\text {NonLinear }}$ and used the tuned model for 12 months ahead forecasts. We applied lag1, lag2, and lag 3 of the TS as inputs to the MLP with two hidden layers. Layer one consists of one neuron. We performed hyperparameter tuning to get the number of neurons in layer two $(\mathrm{N})$ and obtain the optimized model. The hyperparameter search space is: $\mathrm{N}=$ $\{1,2,3,4,5\}$. The $\mathrm{N}$ value of the tuned model is the value at which the forecast-MAPE is the lowest. Figure 5 presents the flowchart of the hyperparameter tuning of the proposed MLP.

For each $\mathrm{WPI}_{\text {NonLinear, we trained twenty-five }}$ networks, combined their forecasts, and obtained an ensemble forecast. We combined them using the mode operator (based on the estimation of kernel density). We used the mlp () of R's nnfor package to build the models [30].
For each $\mathrm{WPI}_{\text {NonLinear, we built the mlp model using }}$ its corresponding tuned hyperparameter and performed twelve months ahead forecasts.

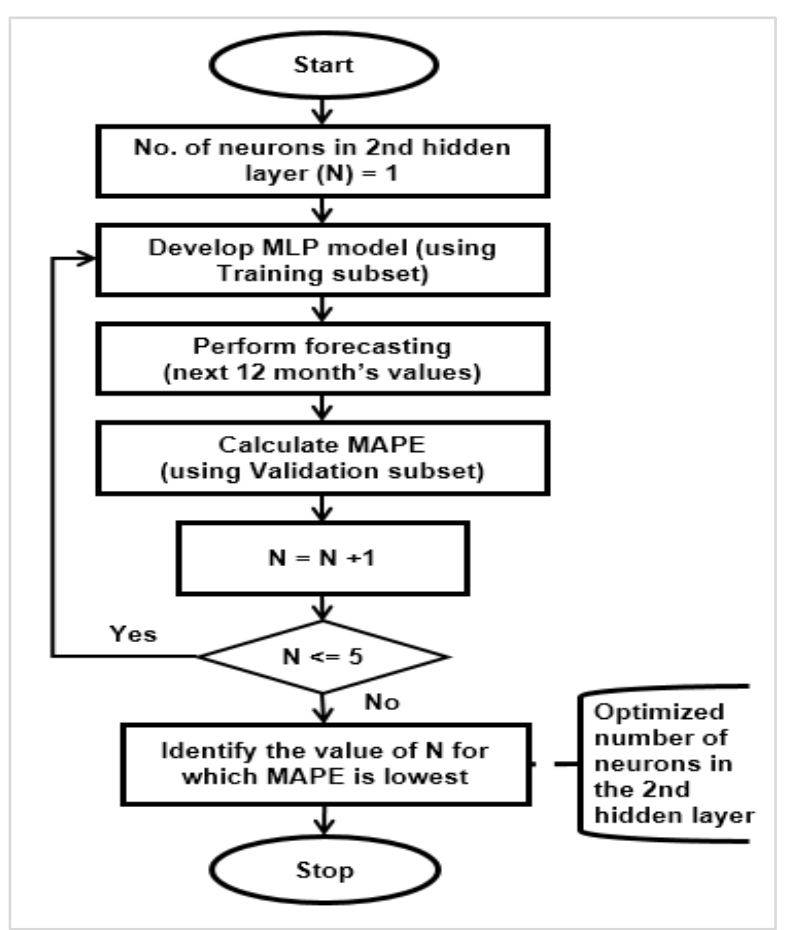

Figure 5 Hyperparameter tuning of the proposed MLP for $\mathrm{WPI}_{\text {NonLinear }}$

3.6Forecast model building for the WPI NonLinear using other approaches (Step6)

In this work, we employed widely accepted and used TS forecasting approaches to forecast and compared their performances with the proposed MLP. For each WPI $_{\text {NonLinear, }}$ we developed the following models:

- Regression [31, 32]: Linear (L1), Quadratic (Q), Cubic (C), Logarithmic (L2), and Exponential (E)

- Exponential smoothing [5, 6]: Holt's linear trend (H1), Holt's exponential trend (H2), and HoltWinters (HW)

- Auto ARIMA (A) [33, 34]

- SVR $[10,14]$

We used R's stats package to build the regression models [29]. To develop the exponential smoothing and automatic ARIMA models, we employed $\mathrm{R}$ software's forecast package [35, 36]. We applied $\mathrm{R}$ software e1071 package [37] for developing the SVR model. For each $\mathrm{WPI}_{\text {NonLinear }}$ using each model, we performed twelve months ahead forecasts. 
3.7Forecasting performance evaluation (Step7)

For each $\mathrm{WPI}_{\text {NonLinear }}$ using each model, we calculated the following accuracy metrics using the forecasts and the test set:

- Mean Absolute Error (MAE) [38]

- Mean Absolute Percentage Error (MAPE) [38]

- Root Mean Squared Error (RMSE) [38]

- Theil's U statistics [39]

We consider the forecast accuracy to be high if the MAPE is less than, equal to ten $[40,41]$ and the forecast to be (i) reliable and (ii) acceptable if Theil's U statistics close to zero [39, 41]. We evaluated the MLP's forecast performances and compared them with others.

\section{Results}

4.1Curve fitting and trend analysis of seventy-

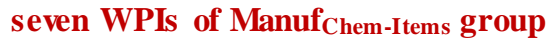

To illustrate the process, we used the WPI of Organic Solvent, applied five models on the training set, and determined the probable best fit. We gave the analys is outcome in Table 1. We developed the following models: L1, Q, C, L2, and E.

Table 1 Result of curve fit of WPI of organic solvent

\begin{tabular}{|c|c|c|c|c|c|}
\hline \multirow{2}{*}{ Fit results } & \multicolumn{5}{|c|}{ Model } \\
\hline & L1 & $\mathbf{Q}$ & $\mathbf{C}$ & L2 & $\mathbf{E}$ \\
\hline $\mathbf{R}^{2}$ & 0.23 & 0.86 & 0.89 & 0.02 & 0.24 \\
\hline $\begin{array}{l}\text { Adjusted } \\
\mathbf{R}^{\mathbf{2}}\end{array}$ & 0.21 & 0.85 & 0.89 & $\overline{0} .001$ & 0.22 \\
\hline F test & 13.55 & 133.39 & 124.52 & 0.94 & 14.64 \\
\hline $\begin{array}{lll}\text { Sig. of } & F \\
\text { test } & & \end{array}$ & $<0.05$ & $<0.05$ & $<0.05$ & 0.34 & $<0.05$ \\
\hline $\begin{array}{l}\text { Competing } \\
\text { models }\end{array}$ & NA & $\sqrt{ }$ & $\sqrt{ }$ & NA & NA \\
\hline AIC & NA & 264.28 & 251.18 & & \\
\hline $\begin{array}{l}\text { Probable } \\
\text { best fit }\end{array}$ & NA & NA & $\sqrt{ }$ & NA & NA \\
\hline
\end{tabular}

Findings: We observed that only two models, namely $\mathrm{Q}$ and $\mathrm{C}$, had both $\mathrm{R}^{2}$ and Adjusted $\mathrm{R}^{2} \geq 0.7$, and the significance of the $\mathrm{F}$ test $<0.05$ and thus met the criteria to become competing models. Model ' $\mathrm{C}$ ' had the lowest AIC, and we identified it as the probable best-fit model.

We illustrated the residual analysis of the identified model in Figure 6.

Findings: The residuals are approximately normally distributed and do not exhibit any outlier. Therefore, the cubic fit is the best.

We employed the curve fitting technique on each seventy-seven indexes, identified their best-fits, and illustrated the summary of findings in Figure 7.

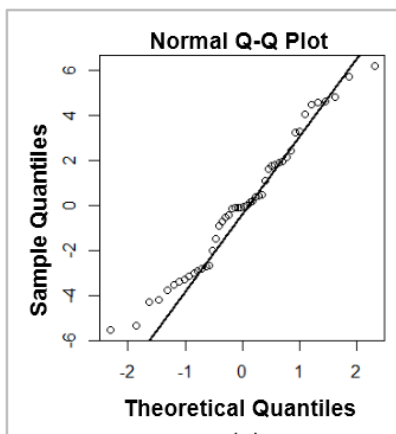

(a)

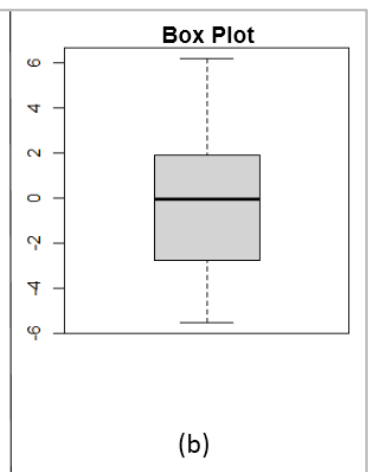

Figure 6 Residual analysis of probable best-fit 'C' model of WPI of organic solvent

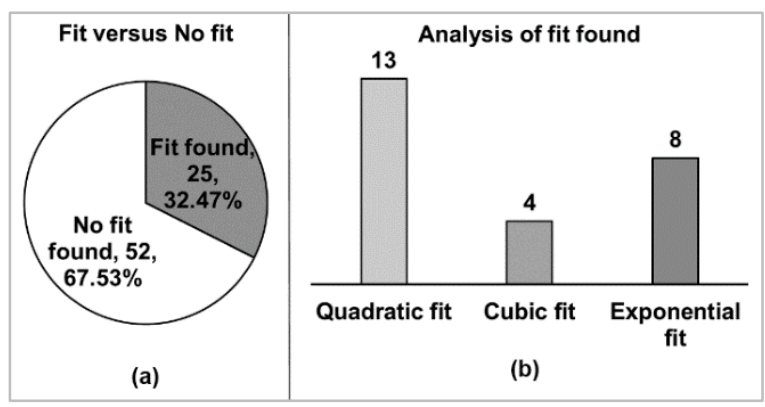

Figure 7 Findings of trend analysis using the curve fit of the seventy-seven WPIs of Manuf Chem-Items group

Findings: We observed that twenty-five out of seventy-seven indices exhibited best fits. The analysis of the fits found is as follows: (i) thirteen WPIs exhibited quadratic, (ii) four WPIs exhibited cubic, and (iii) eight WPIs exhibited exponential fits. Accordingly, we conclude, these twenty-five WPIs exhibit non-linear trends (WPI NonLinear$_{\text {). }}$

We listed the index code (used in this work) of these

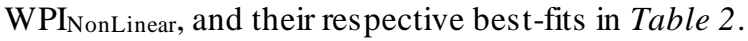

Table 2 List of $\mathrm{WPI}_{\text {NonLinear }}$ of Manuf $\mathrm{fhem}_{\text {-Items }}$ group of India's WPI

\begin{tabular}{llll}
\hline No. & Name of the WPI NonLinear & Index code & Best-fit \\
\hline 1. & Organic Solvent & V1 & C \\
\hline 2. & Dye stuff/dyes incl. dye intermediates and pigments/colours & V2 & C \\
\hline 3. & Acetic acid and Its Derivatives & V3 & C \\
\hline
\end{tabular}


International Journal of Advanced Technology and Engineering Exploration, Vol 8(82)

\begin{tabular}{|c|c|c|c|}
\hline No. & Name of the WPI $_{\text {NonLinear }}$ & Index code & Best-fit \\
\hline 4. & Ethyl acetate & V4 & $\mathrm{C}$ \\
\hline 5. & Ethylene Oxide & V5 & $\mathrm{C}$ \\
\hline 6. & Aniline (including PNA, ONA, OCPNA) & V6 & Q \\
\hline 7. & Nitric Acid & V7 & $\mathrm{E}$ \\
\hline 8. & Liquid air \& other gaseous products & V8 & $\mathrm{E}$ \\
\hline 9. & Alcohols & V9 & $\mathrm{C}$ \\
\hline 10. & Urea & V10 & $\mathrm{E}$ \\
\hline 11. & Ammonia gas & V11 & Q \\
\hline 12. & Poly Vinyl Chloride (PVC) & V12 & $\mathrm{C}$ \\
\hline 13. & Fungicide, liquid & V13 & $\mathrm{E}$ \\
\hline 14. & Varnish (all types) & V14 & $\mathrm{E}$ \\
\hline 15. & Tooth paste/Tooth Powder & V15 & $\mathrm{E}$ \\
\hline 16. & Face/Body Powder & V16 & $\mathrm{E}$ \\
\hline 17. & Mosquito coil & V17 & $\mathrm{E}$ \\
\hline 18. & Poly ester film(metalized) & V18 & $\mathrm{C}$ \\
\hline 19. & Adhesive excluding gum & V19 & $\mathrm{C}$ \\
\hline 20. & Hy drogen peroxide & V20 & $\mathrm{C}$ \\
\hline 21. & Explosive & V21 & Q \\
\hline 22. & Organic chemicals & V22 & $\mathrm{C}$ \\
\hline 23. & Poly ester chips or Poly ethy lene terep thalate (PET) chips & V23 & $\mathrm{C}$ \\
\hline 24. & Viscose staple fibre & V24 & Q \\
\hline 25. & Polyester fibre fabric & V25 & $\mathrm{C}$ \\
\hline
\end{tabular}

\subsection{Forecast model development of the WPI NonLinear} using the proposed MLP approach

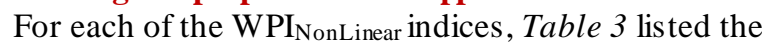
hyperparameter tuning results.

Findings: We performed the hyperparameter tuning to obtain the optimized hyperparameter value, i.e., the number of neurons in the second hidden layer of the MLP for each WPINonLinear. The hyperparameter tuning resulted in the final models for each WPI $_{\text {NonLinear. We observed that the final MLP model }}$ for ten indexes, namely V6, V10, V11, V13, V14, $\mathrm{V} 15$, V16, V17, V20, and V24, obtained 3/1/1/1 configurations. The final model of $\mathrm{V} 7$ is $3 / 1 / 2 / 1$, whereas three indexes, namely V18, V19, and V22, attained 3/1/3/1 configurations. The following seven indexes obtained 3/1/4/1 configurations: V1, V2, V8, $\mathrm{V} 12, \mathrm{~V} 21, \mathrm{~V} 23$, and V25. For the remaining four, i.e., V3, V4, V5, and V9 indexes, 3/1/5/1 is the final model.

Table 3 Final MLP model of each WPI $_{\text {NonLinear index obtained by hyperparameter tuning }}$

\begin{tabular}{|c|c|c|c|c|c|c|}
\hline \multirow{3}{*}{ WPI } & \multicolumn{5}{|c|}{ Hyperparameter tuning } & \multirow{3}{*}{ Final Model } \\
\hline & \multicolumn{5}{|c|}{ MAPE for } & \\
\hline & $\mathrm{N}=1$ & $\mathbf{N}=\mathbf{2}$ & $\mathbf{N}=\mathbf{3}$ & $\mathrm{N}=4$ & $N=5$ & \\
\hline V1 & 10.44 & 10.56 & 10.47 & 10.36 & 10.53 & $3 / 1 / 4 / 1$ \\
\hline $\mathrm{V} 2$ & 14.73 & 14.74 & 14.77 & 14.61 & 14.67 & $3 / 1 / 4 / 1$ \\
\hline V3 & 13 & 13.49 & 13.02 & 12.92 & 12.87 & $3 / 1 / 5 / 1$ \\
\hline V4 & 3.83 & 3.82 & 3.83 & 3.76 & 3.73 & $3 / 1 / 5 / 1$ \\
\hline V5 & 5.746 & 5.746 & 5.735 & 5.729 & 5.728 & $3 / 1 / 5 / 1$ \\
\hline V6 & 4.14 & 4.22 & 4.17 & 4.29 & 4.26 & $3 / 1 / 1 / 1$ \\
\hline V7 & 6.61 & 6.47 & 6.52 & 6.5 & 6.54 & $3 / 1 / 2 / 1$ \\
\hline V8 & 0.91 & 0.96 & 0.91 & 0.82 & 0.89 & $3 / 1 / 4 / 1$ \\
\hline V9 & 5.821 & 5.436 & 5.41 & 5.436 & 5.408 & $3 / 1 / 5 / 1$ \\
\hline V10 & 1.24 & 1.6 & 1.52 & 1.64 & 1.65 & $3 / 1 / 1 / 1$ \\
\hline V11 & 17.68 & 17.69 & 17.71 & 17.72 & 17.78 & $3 / 1 / 1 / 1$ \\
\hline V12 & 8.45 & 8.4 & 8.42 & 8.36 & 8.37 & $3 / 1 / 4 / 1$ \\
\hline V13 & 12.68 & 12.71 & 12.68 & 12.71 & 12.7 & $3 / 1 / 1 / 1$ \\
\hline V14 & 5.53 & 5.54 & 5.57 & 5.55 & 5.56 & $3 / 1 / 1 / 1$ \\
\hline V15 & 2.98 & 3.05 & 3.02 & 3.04 & 3.03 & $3 / 1 / 1 / 1$ \\
\hline V16 & 1.2 & 1.24 & 1.25 & 1.23 & 1.25 & $3 / 1 / 1 / 1$ \\
\hline V17 & 3.83 & 4.6 & 7.08 & 6.98 & 6.98 & $3 / 1 / 1 / 1$ \\
\hline
\end{tabular}




\begin{tabular}{lllllll}
\hline \multirow{2}{*}{ WPI } & \multicolumn{5}{c}{ Hyperparameter tuning } & \multirow{2}{*}{ Final Model } \\
\cline { 2 - 6 } & $\mathbf{5}$ & $\mathbf{N}=\mathbf{2}$ & $\mathbf{N = 3}$ & $\mathbf{N}=\mathbf{4}$ & $\mathbf{N = 5}$ \\
\hline & $\mathbf{N}$ & 5.171 & 5.147 & 5.17 & 5.152 & $3 / 1 / 3 / 1$ \\
\hline V18 & 5.181 & 2.18 & 2.17 & 2.19 & 2.17 & $3 / 1 / 3 / 1$ \\
\hline V19 & 2.18 & 8.26 & 8.24 & 8.27 & 8.24 & $3 / 1 / 1 / 1$ \\
\hline V20 & 8.13 & 1.341 & 1.326 & 1.324 & 1.357 & $3 / 1 / 4 / 1$ \\
\hline V21 & 1.339 & 3.9 & 3.897 & 3.9 & 3.889 & $3 / 1 / 3 / 1$ \\
\hline V22 & 3.905 & 10.93 & 11.13 & 10.37 & 11.37 & $3 / 1 / 4 / 1$ \\
\hline V23 & 11.2 & 1.5 & 1.57 & 1.55 & 1.57 & $3 / 1 / 1 / 1$ \\
\hline V24 & 1.4 & 4.69 & 3.98 & 3.96 & 4.01 & $3 / 1 / 4 / 1$ \\
\hline V25 & 4.24 & & &
\end{tabular}

4.3Forecasting performance of the MLP

Table 4 lists the forecasting performances of the MLP.

Table 4 Performance of the MLP for forecasting the WPI $_{\text {NonLinear }}$

\begin{tabular}{llll}
\hline $\begin{array}{l}\text { Forecast } \\
\text { accuracy } \\
\text { metrics }\end{array}$ & Criteria & $\begin{array}{l}\text { No. of indices } \\
\text { meeting } \\
\text { criteria }\end{array}$ & Remarks \\
\hline MAPE & $\leq 10$ & 25 & $\begin{array}{l}\text { High model } \\
\text { accuracy }\end{array}$ \\
\hline $\begin{array}{l}\text { Theil's U } \\
\text { statistics }\end{array}$ & $\begin{array}{l}\text { Close to } \\
\text { zero }\end{array}$ & 25 & $\begin{array}{l}\text { Forecast is (i) } \\
\text { reliable and (ii) } \\
\text { acceptable }\end{array}$ \\
\hline
\end{tabular}

Findings: The MLP (proposed model) exhibits high model accuracy, along with reliable and acceptable forecasting for twenty-five out of twenty-five $\mathrm{WPI}_{\text {NonLinear indices. }}$

\subsection{Comparis on of forecast accuracies}

We performed a comparative analysis of the forecast accuracies of the MLP (proposed) with the forecast accuracies of the following models: L1, Q, C, L2, E, $\mathrm{H} 1, \mathrm{H} 2$, HW, A. We assumed that a model's forecasting performance is best if its forecast accuracy metric is less (than the other). We evaluated forecast accuracy metrics of the MLP with each of the nine models individually, counted the indices for which the proposed MLP performed best, and displayed the results in Table 5.

Table 5 Comparis on of forecast accuracies of the MLP with nine models

\begin{tabular}{|c|c|c|c|}
\hline Models & Category & $\begin{array}{l}\text { No. of WPI } \\
\text { (MLP best) }\end{array}$ & $\begin{array}{l}\text { Total no. of } \\
\text { WPI }\end{array}$ \\
\hline \multirow[t]{5}{*}{ MLP and L1 } & $\mathrm{MAE}_{\mathrm{MLP}}<\mathrm{MAE}_{\mathrm{L} 1}$ & 22 & 25 \\
\hline & MAPE $_{\mathrm{MLP}}<\mathrm{MAPE}_{\mathrm{L} 1}$ & 22 & 25 \\
\hline & $\mathrm{RMSE}_{\mathrm{MLP}}<\mathrm{RMSE}_{\mathrm{L} 1}$ & 20 & 25 \\
\hline & Theil's UMLP $<$ & 20 & 25 \\
\hline & Theil's UL1 & & \\
\hline \multirow[t]{4}{*}{ MLP and Q } & $\mathrm{MAE}_{\mathrm{MLP}}<\mathrm{MAE}$ & 23 & 25 \\
\hline & $\mathrm{MAPE}_{\mathrm{MLP}}<\mathrm{MAPE}_{\mathrm{Q}}$ & 23 & 25 \\
\hline & $\mathrm{RMSE}_{\mathrm{MLP}}<\mathrm{RMSE}_{\mathrm{Q}}$ & 23 & 25 \\
\hline & Theil's $U_{M L P}<$ Theil's $U_{Q}$ & 23 & 25 \\
\hline \multirow[t]{4}{*}{ MLP and $\mathrm{C}$} & $\mathrm{MAE}_{\mathrm{MLP}}<\mathrm{MAE}_{\mathrm{C}}$ & 22 & 25 \\
\hline & $\mathrm{MAPE}_{\mathrm{MLP}}<\mathrm{MAPE}_{\mathrm{C}}$ & 22 & 25 \\
\hline & $\mathrm{RMSE}_{\mathrm{MLP}}<\mathrm{RMSE}_{\mathrm{C}}$ & 22 & 25 \\
\hline & Theil's UMLP $<$ Theil's UC & 22 & 25 \\
\hline \multirow[t]{4}{*}{ MLP and L2 } & $\mathrm{MAE}_{\mathrm{MLP}}<\mathrm{MAE}_{\mathrm{L} 2}$ & 18 & 25 \\
\hline & MAPE $_{\mathrm{MLP}}<\mathrm{MAPE}_{\mathrm{L} 2}$ & 18 & 25 \\
\hline & $\mathrm{RMSE}_{\mathrm{MLP}}<\mathrm{RMSE}_{\mathrm{L} 2}$ & 17 & 25 \\
\hline & $\begin{array}{l}\text { Theil's UMLP } \\
\text { Theil's UL2 }\end{array}$ & 17 & 25 \\
\hline \multirow[t]{4}{*}{ MLP and E } & $\mathrm{MAE}_{\mathrm{MLP}}<\mathrm{MAE}_{\mathrm{E}}$ & 22 & 25 \\
\hline & $\mathrm{MAPE}_{\mathrm{MLP}}<\mathrm{MAPE}_{\mathrm{E}}$ & 22 & 25 \\
\hline & $\mathrm{RMSE}_{\mathrm{MLP}}<\mathrm{RMSE}_{\mathrm{E}}$ & 20 & 25 \\
\hline & $\begin{array}{l}\text { Theil's U ULP } \\
\text { Theil's U }\end{array}$ & 20 & 25 \\
\hline MLP and H1 & $\mathrm{MAE}_{\mathrm{MLP}}<\mathrm{MAE}_{\mathrm{H} 1}$ & 19 & 25 \\
\hline
\end{tabular}




\begin{tabular}{|c|c|c|c|}
\hline Models & Category & $\begin{array}{l}\text { No. of WPI } \\
\text { (MLP best) }\end{array}$ & $\begin{array}{l}\text { Total no. of } \\
\text { WPI }\end{array}$ \\
\hline & MAPE $_{\mathrm{MLP}}<\mathrm{MAPE}_{\mathrm{H} 1}$ & 20 & 25 \\
\hline & $\mathrm{RMSE}_{\mathrm{MLP}}<\mathrm{RMSE}_{\mathrm{H} 1}$ & 18 & 25 \\
\hline & $\begin{array}{l}\text { Theil's U ULP } \\
\text { Theil's UH1 }\end{array}$ & 18 & 25 \\
\hline \multirow[t]{4}{*}{ MLP and H2 } & $\mathrm{MAE}_{\mathrm{MLP}}<\mathrm{MAE}_{\mathrm{H} 2}$ & 19 & 25 \\
\hline & MAPE $_{M L P}<$ MAPE $_{\mathrm{H} 2}$ & 19 & 25 \\
\hline & $\mathrm{RMSE}_{\mathrm{MLP}}<\mathrm{RMSE}_{\mathrm{H} 2}$ & 19 & 25 \\
\hline & $\begin{array}{l}\text { Theil's UMLP } \\
\text { Theil's UH2 }\end{array}$ & 19 & 25 \\
\hline \multirow[t]{4}{*}{ MLP and HW } & $\mathrm{MAE}_{\mathrm{MLP}}<\mathrm{MAE}_{\mathrm{HW}}$ & 18 & 25 \\
\hline & MAPE $_{M L P}<$ MAPE $_{H W}$ & 18 & 25 \\
\hline & $\mathrm{RMSE}_{\mathrm{MLP}}<\mathrm{RMSE}_{\mathrm{HW}}$ & 17 & 25 \\
\hline & $\begin{array}{l}\text { Theil's UMLP }< \\
\text { Theil's UHW }\end{array}$ & 17 & 25 \\
\hline \multirow[t]{4}{*}{ MLP and $\mathrm{A}$} & $\mathrm{MAE}_{\mathrm{MLP}}<\mathrm{MAE}_{\mathrm{A}}$ & 13 & 25 \\
\hline & MAPE $_{M L P}<$ MAPEA $_{A}$ & 14 & 25 \\
\hline & $\mathrm{RMSE}_{\mathrm{MLP}}<\mathrm{RMSE}_{\mathrm{A}}$ & 13 & 25 \\
\hline & $\begin{array}{l}\text { Theil's U ULP } \\
\text { Theil's UA }\end{array}$ & 13 & 25 \\
\hline
\end{tabular}

Findings: The proposed MLP surpassed others in connection with the total number of good performances for all four-accuracy metrics when compared individually.

For each WPINonLinear, we performed a comparison to find out which model performs best. We picked out the best-performing model amongst all compared

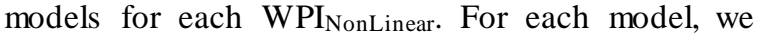
counted the total best performances. The overall comparison of the models shown in Figure 8 represents the number of best-performances of each model.

\begin{tabular}{|c|c|c|c|}
\hline \multicolumn{2}{|c|}{$\begin{array}{l}\text { Best performance of the models } \\
\text { based on MAE }\end{array}$} & \multicolumn{2}{|c|}{$\begin{array}{l}\text { Best performance of the models } \\
\text { based on MAPE }\end{array}$} \\
\hline $\begin{array}{r}\text { Proposed MLP } \\
\text { Auto ARIMA } \\
\text { Logarithmic }\end{array}$ & \begin{tabular}{|l} 
\\
\end{tabular} & \multirow{8}{*}{ 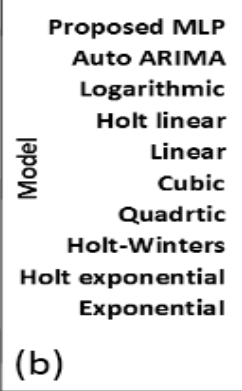 } & \multirow{7}{*}{ 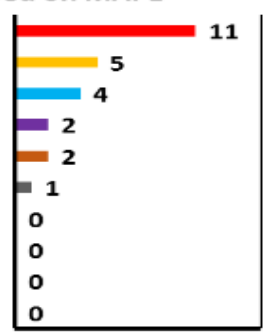 } \\
\hline Holt linear & 2 & & \\
\hline Linear & 2 & & \\
\hline $\begin{array}{r}\text { Cubic } \\
\text { Quadrtic }\end{array}$ & & & \\
\hline Holt-Winters & 0 & & \\
\hline Holt exponential & 0 & & \\
\hline Exponential & o & & \\
\hline (a) & ${ }^{0}$ Count of indices 15 & & ${ }^{\circ}$ Count of indices 15 \\
\hline \multicolumn{2}{|c|}{$\begin{array}{c}\text { Best performance of the models } \\
\text { based on RMSE }\end{array}$} & \multicolumn{2}{|c|}{$\begin{array}{l}\text { Best performance of the models } \\
\text { based on Theil's } U\end{array}$} \\
\hline $\begin{array}{r}\text { Proposed MLP } \\
\text { Auto ARIMA } \\
\text { Logarithmic }\end{array}$ & $4^{-6}{ }^{9}$ & $\begin{array}{r}\text { Proposed MLP } \\
\text { Auto ARIMA } \\
\text { Logarithmic }\end{array}$ & ${ }_{4} 69$ \\
\hline Holt linear & $=2$ & Holt linear & 2 \\
\hline Linear & 2 & Linear & 2 \\
\hline $\begin{array}{r}\text { Cubic } \\
\text { Quadrtic }\end{array}$ & $=1$ & $\begin{array}{r}\text { Cubic } \\
\text { Oradrtic }\end{array}$ & 1 \\
\hline Holt-Winters & 0 & Holt-Winters & 0 \\
\hline Holt exponential & 0 & Holt exponential & o \\
\hline Exponential & 0 & Exponential & o \\
\hline (c) & ${ }^{0}$ Count of indices 15 & (d) & ${ }^{0}$ Count of indices ${ }^{15}$ \\
\hline
\end{tabular}

Figure 8 Total number of best performances of each model 
Findings: The proposed MLP surpassed others in connection with the total number of good performances for all four-accuracy metrics when compared collectively.

Using different MAPE criteria, we examined the forecast MAPE of nine applied models and the proposed MLP, and Table 6 presents the results.

Table 6 Model comparison using different forecast MAPE criteria

\begin{tabular}{lll}
\hline \multirow{2}{*}{ Model } & \multicolumn{2}{l}{$\begin{array}{l}\text { The total number of indices, } \\
\text { meeting the criteria }\end{array}$} \\
\cline { 2 - 3 } & MAPE $\leq \mathbf{1 0}$ & MAPE $\leq \mathbf{7 . 5}$ \\
\hline L1 & 22 & 17 \\
\hline Q & 13 & 9 \\
\hline C & 11 & 8 \\
\hline L2 & 21 & 15 \\
\hline E & 21 & 17 \\
\hline H1 & 21 & 17 \\
\hline H2 & 22 & 17 \\
\hline HW & 23 & 20 \\
\hline A & 25 & 24 \\
\hline Proposed MLP approach & 25 & 25 \\
\hline
\end{tabular}

Findings: Except for model A, the proposed MLP bettered others in connection with the total number of indices, meeting the following criteria: (i) MAPE $\leq$ 10 and (ii) $\mathrm{MAPE} \leq 7.5$. For MAPE $\leq 10$, models 'A' and MLP performed the same. The MLP bettered model ' $\mathrm{A}$ ' in connection with the other criterion, i.e., $\mathrm{MAPE} \leq 7.5$.

Notwithstanding the encouraging forecasting performances of the MLP-proposed and to test the prudence of this MLP approach, we compared the forecasting performance of the MLP with the SVR another popular machine learning (ML) approach.

We performed hyperparameter tuning of the SVR model for each $\mathrm{WPI}_{\text {NonLinear }}$ and used the tuned model for 12 months ahead forecasts. We applied the RBF kernel for model development. For hyperparameter tuning, we used the training subset (to develop the model) and the validation subset (to calculate forecast-MAPE). The hyperparameter search space is given by gamma $(\gamma)=\{1,1.25,1.5,1.75,2\}$. The gamma value of the tuned model is the value at which the forecast-MAPE is the lowest. Figure 9 presents the flowchart of the hyperparameter tuning of the SVR. Table 7 listed the hyperparameter tuning results of the SVR approach for each of these twentyfive indices.

For each $\mathrm{WPI}_{\text {NonLinear }}$ indices, we compared the SVR and the proposed MLP's forecast performance and identified the best-performing model. We counted the number of $\mathrm{WPI}_{\text {NonLinear indexes for which the MLP }}$ performed best and displayed the results in Table 8 .

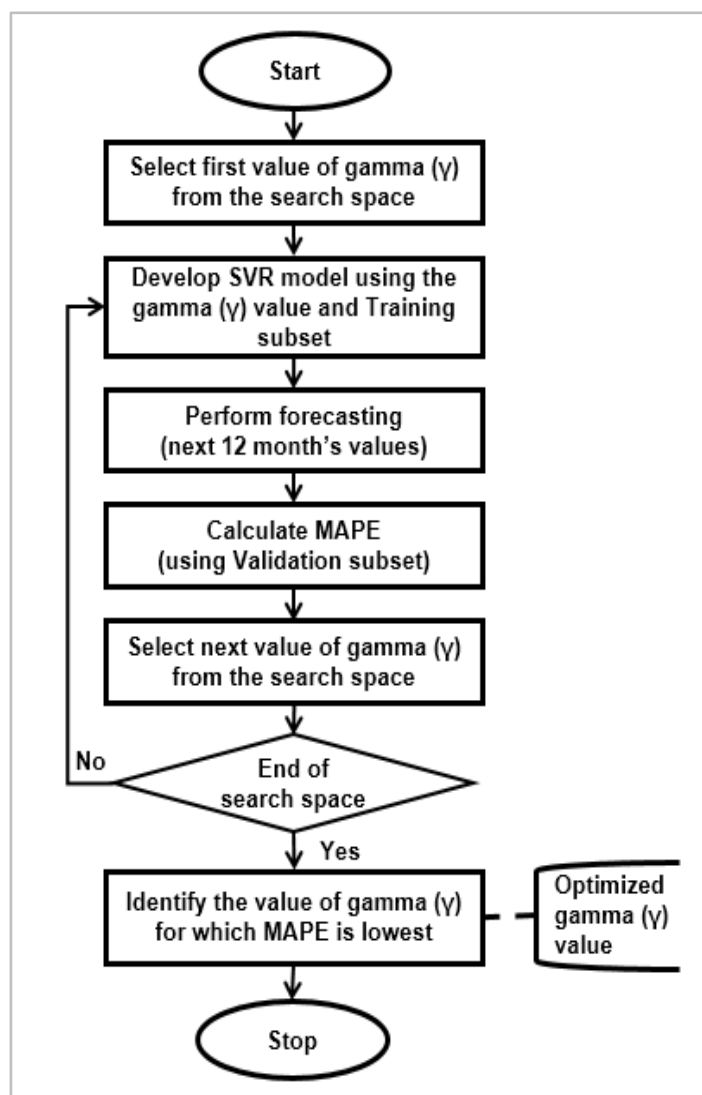

Figure 9 Hyperparameter tuning of SVR for WPI $I_{\text {NonLinear }}$

Table 7 Hyperparameter tuning and optimized Gamma of the SVR models for twenty-five WPI NonLinear indices

\begin{tabular}{|c|c|c|c|c|c|c|}
\hline \multirow{3}{*}{ WPI } & \multicolumn{5}{|c|}{ Hyperparameter tuning } & \multirow{3}{*}{$\begin{array}{c}\text { Optimized } \\
\gamma\end{array}$} \\
\hline & \multicolumn{5}{|c|}{ MAPE for } & \\
\hline & $\gamma=1$ & $\gamma=1.25$ & $\gamma=1.5$ & $\gamma=1.75$ & $\gamma=2$ & \\
\hline V1 & 10.44 & 10.56 & 10.47 & 10.36 & 10.53 & 1.75 \\
\hline V2 & 14.73 & 14.74 & 14.77 & 14.61 & 14.67 & 1.75 \\
\hline $\mathrm{V} 3$ & 13.00 & 13.49 & 13.02 & 12.92 & 12.87 & 2 \\
\hline V4 & 3.83 & 3.82 & 3.83 & 3.76 & 3.73 & 2 \\
\hline
\end{tabular}




\begin{tabular}{|c|c|c|c|c|c|c|}
\hline \multirow{3}{*}{ WPI } & \multicolumn{5}{|c|}{ Hyperparameter tuning } & \multirow{3}{*}{$\begin{array}{c}\text { Optimized } \\
\gamma\end{array}$} \\
\hline & \multicolumn{5}{|c|}{ MAPE for } & \\
\hline & $\gamma=1$ & $\gamma=1.25$ & $\gamma=1.5$ & $\gamma=1.75$ & $\gamma=2$ & \\
\hline V5 & 5.75 & 5.75 & 5.73 & 5.73 & 5.73 & 2 \\
\hline V6 & 4.14 & 4.22 & 4.17 & 4.29 & 4.26 & 1 \\
\hline V7 & 6.61 & 6.47 & 6.52 & 6.50 & 6.54 & 1.25 \\
\hline V8 & 0.91 & 0.96 & 0.91 & 0.82 & 0.89 & 1.75 \\
\hline V9 & 5.82 & 5.44 & 5.41 & 5.44 & 5.41 & 2 \\
\hline V10 & 1.24 & 1.60 & 1.52 & 1.64 & 1.65 & 1 \\
\hline V11 & 17.68 & 17.69 & 17.71 & 17.72 & 17.78 & 1 \\
\hline V12 & 8.45 & 8.40 & 8.42 & 8.36 & 8.37 & 1.75 \\
\hline V13 & 12.68 & 12.71 & 12.68 & 12.71 & 12.70 & 1 \\
\hline V14 & 5.53 & 5.54 & 5.57 & 5.55 & 5.56 & 1 \\
\hline V15 & 2.98 & 3.05 & 3.02 & 3.04 & 3.03 & 1 \\
\hline V16 & 1.20 & 1.24 & 1.25 & 1.23 & 1.25 & 1 \\
\hline V17 & 3.83 & 4.60 & 7.08 & 6.98 & 6.98 & 1 \\
\hline V18 & 5.18 & 5.17 & 5.15 & 5.17 & 5.15 & 1.5 \\
\hline V19 & 2.18 & 2.18 & 2.17 & 2.19 & 2.17 & 1.5 \\
\hline V20 & 8.13 & 8.26 & 8.24 & 8.27 & 8.24 & 1 \\
\hline V21 & 1.34 & 1.34 & 1.33 & 1.32 & 1.36 & 1.75 \\
\hline V22 & 3.90 & 3.90 & 3.90 & 3.90 & 3.90 & 1.5 \\
\hline V23 & 11.20 & 10.93 & 11.13 & 10.37 & 11.37 & 1.75 \\
\hline V24 & 1.40 & 1.50 & 1.57 & 1.55 & 1.57 & 1 \\
\hline V25 & 4.24 & 4.69 & 3.98 & 3.96 & 4.01 & 1.75 \\
\hline
\end{tabular}

Table 8 Comparison of the SVR and the proposed MLP's forecast accuracies

\begin{tabular}{|c|c|c|c|}
\hline Models & Category & $\begin{array}{l}\text { No. of } \\
\text { WPI } \\
\text { (MLP } \\
\text { best) }\end{array}$ & $\begin{array}{l}\text { Total } \\
\text { no. } \\
\text { of } \\
\text { WPI }\end{array}$ \\
\hline \multirow{4}{*}{$\begin{array}{l}\text { MLP } \\
\text { and } \\
\text { SVR }\end{array}$} & MAE $_{M L P}<$ MAESVR & 14 & 25 \\
\hline & MAPE $_{M L P}<$ MAPE $_{S V R}$ & 14 & 25 \\
\hline & RMSE $_{M L P}<$ RMSE $_{S V R}$ & 14 & 25 \\
\hline & Theil's UMLP $<$ Theil's USVR & 14 & 25 \\
\hline
\end{tabular}

Findings: The proposed MLP surpassed the SVR in connection with the total number of best performances for all four accuracy metrics.

Using different MAPE criteria, we examined the forecast MAPE of the SVR and the proposed MLP, and Table 9 presents the results.
Table 9 Comparison of Proposed MLP and SVR using different MAPE criteria

\begin{tabular}{lll}
\hline \multirow{2}{*}{ Model } & $\begin{array}{l}\text { Total number of indices } \\
\text { meeting the criteria }\end{array}$ \\
\cline { 2 - 3 } & MAPE $\leq \mathbf{1 0}$ & MAPE $\leq \mathbf{7 . 5}$ \\
\hline Proposed MLP & 25 & 25 \\
\hline SVR & 22 & 22 \\
\hline
\end{tabular}

Findings: The MLP is a clear winner for both MAPE less than equal to 10 and 7.5.

We analyzed the forecasting performances of our proposed model with the MLP models of Khashei and Hajirahimi [42], Lu et al. [43], and Herrera et al. [44] and listed the findings in Table 10.

Table 10 Performance comparis on of the proposed MLP with the MLP models of others

\begin{tabular}{|c|c|c|c|c|c|}
\hline \multirow[t]{2}{*}{ Authors } & \multirow[t]{2}{*}{ Details } & \multirow[t]{2}{*}{ Forecast horizon } & \multicolumn{3}{|c|}{ Forecast accuracy metrics } \\
\hline & & & MAE & RMSE & MAPE \\
\hline \multirow{3}{*}{$\begin{array}{l}\text { Khashei and } \\
\text { Hajirahimi } \\
(2019) \text { [42] }\end{array}$} & $\begin{array}{l}\text { Dow Jones Industrial Average } \\
\text { Index }\end{array}$ & $\begin{array}{l}60 \text { months ( } 25 \% \text { of the total number } \\
\text { of observations) }\end{array}$ & 366.81 & 471.09 & 3.48 \\
\hline & Shenzhen Integrated Index & $\begin{array}{l}48 \text { months ( } 23 \% \text { of the total number } \\
\text { of observations) }\end{array}$ & 1102.34 & 1405.16 & 9.81 \\
\hline & Nikkei 225 & $\begin{array}{l}201 \text { days ( } 20 \% \text { of the total number } \\
\text { of observations) }\end{array}$ & 100.03 & 123.29 & 0.98 \\
\hline $\begin{array}{l}\text { Lu et al. } \\
(2020)[43]\end{array}$ & $\begin{array}{lll}\text { Shanghai } & \text { Composite Index } \\
(000001) & & \\
\end{array}$ & $\begin{array}{l}500 \text { days (approximately } 7 \% \text { of the } \\
\text { total number of observations) }\end{array}$ & 37.58 & 49.80 & \\
\hline \multirow{2}{*}{$\begin{array}{l}\text { Herrera et al. } \\
(2019)[44]\end{array}$} & Oil Brent & \multirow{2}{*}{$\begin{array}{l}20 \% \text { (app) of the total number of } \\
\text { observations }\end{array}$} & & 17.34 & 17.92 \\
\hline & Oil WTI & & & 14.72 & 16.56 \\
\hline
\end{tabular}




\begin{tabular}{|c|c|c|c|c|c|}
\hline \multirow[t]{6}{*}{ Authors } & \multirow[t]{2}{*}{ Details } & \multirow[t]{6}{*}{ Forecast horizon } & \multicolumn{3}{|c|}{ Forecast accuracy metrics } \\
\hline & & & MAE & RMSE & MAPE \\
\hline & Oil Dubai & & & 20.29 & 20.43 \\
\hline & Coal AU & & & 12.80 & 11.54 \\
\hline & Gas US & & & 0.78 & 23.72 \\
\hline & Gas Russia & & & 2.68 & 32.88 \\
\hline Our work & $\begin{array}{l}\text { Twenty-five non-linear trends } \\
\text { exhibiting WPI of the } \\
\text { Manuf Chem-Items group of India }\end{array}$ & $\begin{array}{l}12 \text { months ( } 20 \% \text { of the total number } \\
\text { of observations) }\end{array}$ & $0.64 *$ & $0.81 *$ & $0.56^{*}$ \\
\hline
\end{tabular}

* Best performance of the proposed MLP obtained for index V2

Findings: The proposed MLP surpassed others in connection with the best performances for the threeaccuracy metrics - MAE, RMSE, and MAPE.

A complete list of abbreviations is shown in Appendix I.

\section{Discussions}

In this work, the authors intended to develop a simple (implementation wise), efficient (forecast accuracy wise), and state-of-art MLP approach for the nonlinear indexes of the ManufChem-Items group from the Indian WPI series for bridging the gaps identified from the past studies. The outcomes of the present work are as follows:

- We observed that twenty-five out of seventy-seven WPIs, i.e., thirty-two point four seven percent exhibited non-linear fits. The rest of the WPIs (67.53\%) could not found any fits. In this present work, we focused on only the WPIs with nonlinear fits identified through curve fitting.

- For forecasting the WPINonLinear indices, we proposed and developed a simple and efficient MLP approach. The model exhibits high model accuracy (MAPE $\leq$ ten), along with reliable and acceptable forecasting (Theil's U statistics close to zero) for twenty-five out of twenty-five indices, i.e., for hundred percent cases.

- We compared the forecast accuracies (MAE, MAPE, RMSE, and Theil's U) of the proposed MLP with the other applied models (L1, Q, C, L2, E, H1, H2, HW, A, and SVR). We observed that the proposed MLP exhibited the lowest MAE, MAPE, RMSE, and Theil's U statistics for the maximum number of indices when compared MLP versus a single model (i.e., individual comparison) and MLP versus all models (i.e., compared collectively). Therefore, we witnessed the model (MLP) achieved better forecast accuracies than others and outperformed others.

- The precision of the proposed MLP is also better than others. For the proposed MLP, the count of the total number of indices showing forecast-
MAPE less than equal to seven point five is twenty-five out of twenty-five, higher than all other models applied.

\subsection{Limitations}

We proposed and developed an MLP approach for the WPINonLinear indexes of the ManufChem-Items group from the Indian WPI series. Out of seventyseven WPIs, fifty-two WPIs could not exhibit any best fit and therefore remain out of the scope of this work. We have not examined the performance of the proposed MLP on these sets of WPIs to judge the forecastability of our proposed model on the TS dataset that could not show any clear trends. In the present work, we compared the performance of the proposed model on a limited set (twenty-five) of WPIs exhibiting non-linear trends. Exploring the hyperparameters (e.g., number of hidden layers, number of neurons) of the MLP is another challenging area for future work.

\section{Conclusion and future work}

Time-series forecasting acts as an instrument of decision-making, produces estimations about the future based on historical data. The suggestion of an appropriate forecasting strategy that is simple (implementation wise) and efficient (forecast accuracy wise) for a time-series dataset and that (proposed approach) can act as a convenient alternative is challenging. This work provides a stateof-art alternative forecasting strategy for some selected WPIs in India. The proposed method applies the MLP - a neural approach to model and forecast the non-linear WPIs. For each WPI, the proposedMLP employs historical data of the univariate series as inputs, uses optimized hyperparameter, trains multiple networks, combines their forecast values, and obtains an ensemble forecast. We looked at the WPIs with non-linear trends identified using the curve-fit method. The curve-fit approach based on statistical rigor identifies the non-linear WPIs.

The chemical industry is a multiple-product industry and one of the fastest-growing in India. There are 
seventy-seven individual items in the Manuf $\mathrm{Chem}_{\text {-Items }}$ group of India's present WPI. Identification of the trends of these seventy-seven WPIs and proposing an efficient forecasting approach for the WPIs from the group that exhibits non-linear trends is indeed challenging. In this work, we identified the WPIs of the Manuf Chem-Items $_{\text {group with non-linear trends and }}$ proposed an efficient forecasting approach for them. We analyzed each of the seventy-seven WPIs of the ManufChem-Items group exercising curve fitting, identified the WPIs with non-linear trends (WPINonLinear), and developed a forecasting approach applying MLP for these WPI $\mathrm{WnnLinear}_{\text {indices. The }}$ proposed model is suitable to render twelve months ahead forecasts.

The novel contributions of this work are the following:

- Identification of the WPIs of the Manuf Chem-Items group with non-linear trends using the curve-fit method

- Development of a simple (implementation wise) and efficient (forecast accuracy wise) forecasting approach for these WPIs (i.e., WPI NonLinear indices) by applying MLP

At first, we employed curve fitting to analyze the seventy-seven WPIs and determined the $\mathrm{WPI}_{\text {NonLinear }}$ indices. We observed that twenty-five out of seventyseven WPIs - i.e., approximately thirty-two point five percent of indices exhibit non-linear trends. The majority of the fits are quadratic - i.e., thirteen out of twenty-five.

Next, we developed forecasting models for these twenty-five $\mathrm{WPI}_{\text {NonLinear }}$ indices using the following ten models: (i) MLP (proposed approach), (ii) Linear, (iii) Quadratic, (iv) Cubic, (v) Logarithmic, (vi) Exponential, (vii) Holt linear trend, (viii) Holt exponential trend, (ix) Holt-Winters, and (x) AutoARIMA. The MLP (proposed approach) exhibits high model accuracy, along with reliable and acceptable forecasting for twenty-five out of twentyfive $\mathrm{WPI}_{\text {NonLinear }}$ indices. The proposed approach also surpassed others in connection with the following:

- Total number of best performances when compared individually

- Total number of best performances when compared with all others at the same time

- MAPE less than equal to seven point five

Notwithstanding the promising forecasting performance of the MLP (proposed approach) and to test its prudence, we examined the proposed-MLP's performance against SVR's performance and noted

1205 that the proposed MLP surpassed the SVR in connection with the following:

- Total number of best performances

- MAPE less than equal to ten

- MAPE less than equal to seven point five

According to our findings, the proposed-MLP outperformed the regression, exponential smoothing, Auto ARIMA, and SVR methods on different accuracy metrics applying varied criteria. Therefore, we suggest the proposed MLP is a suitable alternative for forecasting these twenty-five WPINonLinear indices for the next twelve months. Additionally, validating the proposed approaches' accuracy and suitability on different sets of indices with non-linear trends or indices that do not show any trends creates a new research direction. Exploring the hyperparameters of the MLP by expanding the search space to achieve better efficiency is another area in the future scope of this work.

\section{Acknowledgment}

None.

Conflicts of interest

The authors have no conflicts of interest to declare.

\section{References}

[1] Wadi SA, Almasarweh M, Alsaraireh AA, Aqaba J. Predicting closed price time series data using ARIMA model. Modern Applied Science. 2018; 12(11):181-5.

[2] Almasarweh M, Alwadi S. ARIMA model in predicting banking stock market data. Modern Applied Science. 2018; 12(11):309-12.

[3] Miller JW. ARIMA time series models for full truckload transportation prices. Forecasting. 2019; 1(1):121-34.

[4] Talwar A, Goyal CK. A comparative study of various exponential smoothing models for forecasting coriander price in Indian commodity market. International Bulletin of Management and Economics. 2019:143-55.

[5] Suppalakpanya K, Nikhom R, Booranawong T, Booranawong A. Study of several exponential smoothing methods for forecasting crude palm oil productions in Thailand. Current Applied Science and Technology. 2019; 19(2):123-39.

[6] Şahinli MA. Potato price forecasting with holt-winters and ARIM A methods: a case study. American Journal of Potato Research. 2020; 97(4):336-46.

[7] Claveria O, Monte E, Torra S. Modelling tourism demand to Spain with machine learning techniques. The impact of forecast horizon on model selection. arXiv preprint arXiv:1805.00878. 2018.

[8] He XJ. Crude oil prices forecasting: time series vs. SVR models. Journal of International Technology and Information Management. 2018; 27(2):25-42.

[9] Kuizinienė D, Mackutè-varoneckienė A, Krilavičius T. Cryptocurrencies short-term forecast: application of 
ARIMA, GARCH and SVR models. In international conference on information technologies, Kaunas, Lithuania. 2019 (pp.70-3).

[10] Abidoye RB, Chan AP, Abidoye FA, Oshodi OS. Predicting property price index using artificial intelligence techniques: evidence from Hong Kong. International Journal of Housing Markets and Analy sis. 2019; 12(6):1072-92.

[11] Airlangga G, Rachmat A, Lapihu D. Comparison of exponential smoothing and neural network method to forecast rice production in Indonesia. Telkomnika. 2019; 17(3):1367-75.

[12] Spiliotis E, Doukas H, Assimakopoulos V, Petropoulos F. Forecasting week-ahead hourly electricity prices in belgium with statistical and machine learning methods. Mathematical Modelling of Contemporary Electricity Markets 2021:59-74. Academic Press.

[13] Hossain MF, Nandi DC, Uddin KM. Prediction of banking sectors financial data of Dhaka stock exchange using autoregressive integrated moving average approach. International Journal of Material and Mathematical Science. 2020; 2(4):64-70.

[14] Rohmah MF, Putra IK, Hartati RS, Ardiantoro L. Comparison four kernels of SVR to predict consumer price index. In journal of physics: conference series 2021 (pp. 1-9). IOP Publishing.

[15] Marini F. 3.14 - Neural networks. Comprehensive Chemometrics. 2009 : 477-505. Elsevier.

[16] Bertolaccini L, Solli P, Pardolesi A, Pasini A. An overview of the use of artificial neural networks in lung cancer research. Journal of Thoracic Disease. 2017; 9(4):924-31.

[17] https://towardsdatascience.com/introduction-to-neuralnetworks-advantages-and-applications-96851bd1a207. Accessed 10 April 2021.

[18] Azari A. Bitcoin price prediction: an ARIMA approach. arXiv preprint arXiv:1904.05315. 2019.

[19] Zhu W, Li X, Sun B. Research and prediction on china's novel coronavirus (2019-nCoV/COVID-19) epidemic-based on time series ARIMA model. In international conference on education, management, computer and society 2020 (pp.310-16).

[20] Katoch R, Sidhu A. An application of ARIMA model to forecast the dynamics of COVID-19 epidemic in India. Global Business Review. 2021:1-14.

[21] Rasheed A, Ullah MA, Uddin I. PKR exchange rate forecasting through univariate and multivariate time series techniques. NICE Research Journal. 2020; 13(4):49-67.

[22] Sokannit P, Chujai P. Forecasting household electricity consumption using time series models. International Journal of Machine Learning and Computing. 2021; 11(6):380-6.

[23] Li R, Li X, Lu Z. Forecast of gross output value of agriculture and forestry in guangxi based on holtwinters model. In journal of physics: conference series 2021 (pp.1-7). IOP Publishing.

[24] Ali K. Forecasting analysis of share price index in construction companies registered in indonesia stock exchange 2015-2019. Journal of Economics Research and Social Sciences. 2021; 5(1):42-63.

[25] Carrasco R, Astudillo G, Soto I, Chacon M, Fuentealba D. Forecast of copper price series using vector support machines. In international conference on industrial technology and management 2018 (pp. 380-4). IEEE.

[26] Alegado RT, Tumibay GM. Statistical and machine learning methods for vaccine demand forecasting: a comparative analysis. Journal of Computer and Communications. 2020; 8(10):37-49.

[27] Talkhi N, Fatemi NA, Ataei Z, Nooghabi MJ. Modeling and forecasting number of confirmed and death caused COVID-19 in IRAN: a comparison of time series forecasting methods. Biomedical Signal Processing and Control. 2021:1-8.

[28] https://data.gov.in/resources/wholesale-price-indexbase-y ear-2011-12-upto-may-2017. Accessed 01 March 2021.

[29] Team RC. R: a language and environment for statistical computing. 2013.

[30] https://cran.r-project.org/web/ packages/ nnfor/ index.html. Accessed 10 April 2021.

[31] Das D. Data mining of indian stock market from April 2015 to March 2016 using curve fitting technique. International Research Journal of Engineering and Technology. 2016; 3(5):2564-70.

[32] Juarna A. One year stock price prediction and its validity using least square method in MATLAB. International Journal of Advanced Research. 2017; 5(2): 1641-48.

[33] Awan TM, Aslam F. Prediction of daily COVID-19 cases in European countries using automatic ARIMA model. Journal of Public Health Research. 2020; 9(3):227-33.

[34] Yermal L, Balasubramanian P. Application of auto arima model for forecasting returns on minute wise amalgamated data in NSE. In international conference on computational intelligence and computing research 2017 (pp. 1-5). IEEE.

[35] https://pkg.robjhyndman.com/forecast/. Accessed 10 April 2021.

[36] Hyndman RJ, Khandakar Y. Automatic time series forecasting: the forecast package for R. Journal of Statistical Software. 2008; 27(1):1-22.

[37] David M, Evgenia D, Kurt H, Andreas W, Friedrich L. E1071: misc functions of the department of statistics, probability theory group (Formerly: E1071), TU Wien. R Package Version. 2019.

[38] https://www.rdocumentation.org/packages/DescTools/ versions/0.99.36/topics/Measures\%20of\%20Accuracy. Accessed 02 April 2021.

[39] Oshodi OS, Ejohwomu OA, Famakin IO, Cortez P. Comparing univariate techniques for tender price index forecasting: box-jenkins and neural network model. Construction Economics and Building. 2017; 17(3):109-23.

[40] Yadav V, Nath S. Novel hybrid model for daily prediction of PM 10 using principal component analysis and artificial neural network. International 
Journal of Environmental Science and Technology. 2019; 16(6):2839-48.

[41] Fan RY, Ng ST, Wong JM. Reliability of the boxjenkins model for forecasting construction demand covering times of economic austerity. Construction Management and Economics. 2010; 28(3):241-54.

[42] Khashei M, Hajirahimi Z. A comparative study of series ARIMA/MLP hybrid models for stock price forecasting. Communications in Statistics-Simulation and Computation. 2019; 48(9):2625-40.

[43] Lu W, Li J, Li Y, Sun A, Wang J. A CNN-LSTMbased model to forecast stock prices. Complexity. 2020.

[44] Herrera GP, Constantino M, Tabak BM, Pistori H, Su JJ, Naranpanawa A. Long-term forecast of energy commodities price using machine learning. Energy. 2019; 179:214-21.

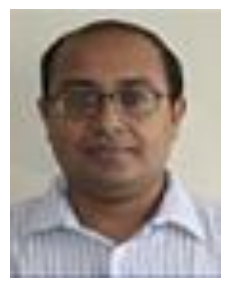

Dipankar Das is a Ph.D. scholar at the University of Engineering \& Management, Kolkata, West Bengal, India. His research interests are Data Analytics, Time Series Analysis, Forecasting, Artificial Intelligence, and Machine Learning.

Email: dipankr.das@gmail.com

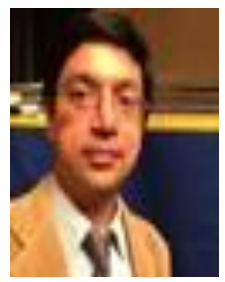

Dr. Satyajit Chakrabarti, Professor, Department of Computer Science and Engineering, University of Engineering \& Management, Kolkata, West Bengal, India. His research interests are Data Science, Data Mining, Artificial Intelligence, and Nano Technology.

Email: satyajit.chakrabarti@iemcal.com

Appendix I

\begin{tabular}{lll}
\hline S. No. & \multicolumn{1}{c}{ Abbreviation } & Description \\
\hline 1 & A & Auto ARIMA \\
\hline 2 & AIC & Akaike's Information Criteria \\
\hline 3 & ANN & Artificial Neural Network \\
\hline 4 & ARIMA & $\begin{array}{l}\text { Auto-Regressive Integrated Moving } \\
\text { Average }\end{array}$ \\
\hline 5 & C & Cubic \\
\hline 6 & CPI & Consumer Price Index \\
\hline 7 & E & Exponential \\
\hline 8 & ES & Exponential Smoothing \\
\hline 10 & H1 & Holt's Linear Trend \\
\hline 11 & HW & Holt's Exponential Trend \\
\hline 12 & L1 & Holt-Winters \\
\hline 13 & L2 & Linear \\
\hline 14 & MAE & Logarithmic \\
\hline 15 & MAE & Mean Absolute Error \\
\hline 16 & MAE & Mean Absolute Error of Auto ARIMA \\
\hline 17 & MAE & Mean Absolute Error ofCubic \\
\hline 18 & MAE & Mean Absolute Error of Exponential \\
\hline 19 & MAE & Mean Absolute Error of Holt's Linear \\
\hline 20 & MAE & Trend \\
\hline 21 & MAE 1 & Mean Absolute Error of Holt's Exponential \\
\hline 12 & & Trend \\
\hline
\end{tabular}

\begin{tabular}{|c|c|c|}
\hline 22 & $\mathrm{MAE}_{\mathrm{L} 2}$ & Mean Absolute Error of Logarithmic \\
\hline 23 & $\mathrm{MAE}_{\mathrm{MLP}}$ & Mean Absolute Error of MLP \\
\hline 24 & $\mathrm{MAE}_{\mathrm{Q}}$ & Mean Absolute Error of Quadratic \\
\hline 25 & MAE $_{S V R}$ & $\begin{array}{l}\text { Mean Absolute Error of Support Vector } \\
\text { Regression }\end{array}$ \\
\hline 26 & Manuf $f_{\text {Chem-Items }}$ & $\begin{array}{l}\text { Manufacture of Chemicals and Chemical } \\
\text { Products }\end{array}$ \\
\hline 27 & MAPE & Mean Absolute Percentage Error \\
\hline 28 & $\mathrm{MAPE}_{\mathrm{A}}$ & $\begin{array}{l}\text { Mean Absolute Percentage Error of Auto } \\
\text { ARIMA }\end{array}$ \\
\hline 29 & $\mathrm{MAPE}_{\mathrm{C}}$ & Mean Absolute Percentage Error ofCubic \\
\hline 30 & MAPEE $_{E}$ & $\begin{array}{l}\text { Mean Absolute Percentage Error of } \\
\text { Exponential }\end{array}$ \\
\hline 31 & MAPE $_{\mathrm{H} 1}$ & $\begin{array}{l}\text { Mean Absolute Percentage Error ofHolt's } \\
\text { linear trend }\end{array}$ \\
\hline 32 & MAPE $_{\mathrm{H} 2}$ & $\begin{array}{l}\text { Mean Absolute Percentage Error of Holt's } \\
\text { exponential trend }\end{array}$ \\
\hline 33 & MAPE $_{H W}$ & $\begin{array}{l}\text { Mean Absolute Percentage Error of Holt- } \\
\text { Winters }\end{array}$ \\
\hline 34 & MAPE $_{\mathrm{L} 1}$ & Mean Absolute Percentage Error of Linear \\
\hline 35 & $\mathrm{MAPE}_{\mathrm{L} 2}$ & $\begin{array}{l}\text { Mean Absolute Percentage Error of } \\
\text { Logarithmic }\end{array}$ \\
\hline 36 & MAPE $_{M L P}$ & Mean Absolute Percentage Error of MLP \\
\hline 37 & MAPE $_{Q}$ & $\begin{array}{l}\text { Mean Absolute Percentage Error of } \\
\text { Quadratic }\end{array}$ \\
\hline 38 & MAPE $_{S V R}$ & $\begin{array}{l}\text { Mean Absolute Percentage Error of } \\
\text { Support Vector Regression }\end{array}$ \\
\hline 39 & ML & Machine Learning \\
\hline 40 & MLP & Multi-Layer Perceptron \\
\hline 41 & MSE & Mean Squared Error \\
\hline 42 & Q & Quadratic \\
\hline 43 & RBF & Radial Basis Function \\
\hline 44 & RMSE & Root Mean Square Error \\
\hline 45 & $\mathrm{RMSE}_{\mathrm{A}}$ & Root Mean Square Error of Auto ARIMA \\
\hline 46 & $\mathrm{RMSE}_{\mathrm{C}}$ & Root Mean Square Error of Cubic \\
\hline 47 & RMSE $_{\mathrm{E}}$ & Root Mean Square Error of Exponential \\
\hline 48 & $\mathrm{RMSE}_{\mathrm{Hl}}$ & $\begin{array}{l}\text { Root Mean Square Error of Holt's linear } \\
\text { trend }\end{array}$ \\
\hline 49 & $\mathrm{RMSE}_{\mathrm{H} 2}$ & $\begin{array}{l}\text { Root Mean Square Error of Holt's } \\
\text { Exponential Trend }\end{array}$ \\
\hline 50 & $\mathrm{RMSE}_{\mathrm{HW}}$ & Root Mean Square Error of Holt-Winters \\
\hline 51 & $\mathrm{RMSE}_{\mathrm{L} 1}$ & Root Mean Square Error of Linear \\
\hline 52 & $\mathrm{RMSE}_{\mathrm{L} 2}$ & Root Mean Square Error of Logarithmic \\
\hline 53 & RMSE ${ }_{M L P}$ & Root Mean Square Error of MLP \\
\hline 54 & RMSE $_{Q}$ & Root Mean Square Error of Quadratic \\
\hline 55 & RMSE $_{S V R}$ & $\begin{array}{l}\text { Root Mean Square Error of Support Vector } \\
\text { Regression }\end{array}$ \\
\hline 56 & SVM & Support Vector Machine \\
\hline 57 & SVR & Support Vector Regression \\
\hline 58 & Theil's $U_{A}$ & Theil's U of Auto ARIMA \\
\hline 59 & Theil's $U_{C}$ & Theil's U ofCubic \\
\hline 60 & Theil's U & Theil's U of Exponential \\
\hline 61 & Theil's UH1 & Theil's U ofHolt's linear trend \\
\hline 62 & Theil's $\mathrm{U}_{\mathrm{H} 2}$ & Theil's U ofHolt's exponential trend \\
\hline 63 & Theil's U UW & Theil's U ofHolt-Winters \\
\hline 64 & Theil's $\mathrm{U}_{\mathrm{L} 1}$ & Theil's U ofLinear \\
\hline 65 & Theil's U $\mathrm{L}_{2}$ & Theil's U of Logarithmic \\
\hline 66 & Theil's U MLP & Theil's U of MLP \\
\hline 67 & Theil's $U_{Q}$ & Theil's U ofQuadratic \\
\hline 68 & Theil's U SVR & Theil's U of Support Vector Regression \\
\hline 69 & TS & Time series \\
\hline 70 & WPI & Wholesale Price Index \\
\hline 71 & WPI $I_{\text {NonLinear }}$ & $\begin{array}{l}\text { WPIs of Manuf } \text { Chem-Items group having non- }_{\text {- }} \text { linear trend }\end{array}$ \\
\hline
\end{tabular}

